\title{
A Estação Experimental de Piracicaba e a modernização tecnológica da agroindústria canavieira (1920 a 1940) ${ }^{1}$
}

Graciela de Souza Oliver e Tamás Szmrecsányi

Unicamp-SP

\section{RESUMO}

O processo de ressurgimento e crescimento da agroindústria canavieira paulista na primeira metade do século XX tem sido analisado sob diferentes enfoques em relação ao desenvolvimento econômico. Enquanto uma parte da literatura indica a crise cafeeira de 1930 como o fato chave para o desencadeamento desse processo, outra, mais recente, vem apresentando e resgatando fatores estruturais anteriores a essa época. Teria sido a tecnologia mais um fator capaz de contribuir para tal mudança? Ou teria sido ela um fenômeno sem precedentes e destituído de elementos sociais na sua constituição e inserção? Este trabalho pretende lançar novos elementos sobre estas perguntas, apresentando as atividades técnico-científicas envolvidas na solução da crise do mosaico em fins da década de 1920 como um fato social passível de ser historicamente interpretado.

Palavras-chave: História da tecnologia. Modernização tecnológica. Agroindústria canavieira.

\section{ABSTRACT:}

Different approaches concerned with economic development have focused their attention on São Paulo state's sugar industry during its recovery and growth in the first half of the 20th century. According to some authors the coffee crisis of 1930 was the main turning point, while others have recently indicated previous structural conditions. To what extent can the new sugarcane varieties be related to those changes of São Paulo's sugar industry? Or, did they represent a simple technical event alien to the society at large? The present paper brings out some new arguments for those questions, placing technology in a social context. Keeping this in view, we direct our analysis to the technological strategies involved in the eradication of sugarcane's mosaic disease during the late twenties.

Keywords: History of technology. Technological change. Sugar industry. 


\section{INTRODUÇÃO}

O episódio da crise do mosaico ${ }^{2}$ nos canaviais paulistas em meados da década de 1920 algumas vezes provocou certas modificações na agroindústria canavieira de São Paulo. Estas importantes transformações precederam e corresponderam à nova fase da agricultura brasileira entre 1930 e 1970, quando ela se voltou para o abastecimento do mercado interno e para o fornecimento de matérias-primas para o setor industrial. Durante esse período, nas regiões mais desenvolvidas do País, a modernização tecnológica da agricultura manteve-se relacionada a uma crescente produtividade do trabalho e do capital investido, mais do que ao aumento da produtividade agronômica, devido à crescente apropriação de terras cultiveis (SZMRECSÁNYI 1990, p. 81). Neste contexto e desde uma perspectiva histórica, recuperar a origem e o processo de modernização tecnológica da agroindústria canavieira paulista equivale a considerar a tecnologia como um fenômeno social amplo, e como um instrumento de manutenção da estrutura fundiária e social.

Assumir esses pressupostos significa compreender que as conseqüências da modernização tecnológica extrapolam os resultados da produção em si. Por essas razões, para identificar esse processo histórico na referida agroindústria, além das habituais análises quantitativas da produção, damos ênfase aos fatores políticos, institucionais e científicos, os quais permitiram a inserção e o contínuo desenvolvimento de tecnologias para o setor (OLIVER, 2001). Com tal propósito analisaremos neste artigo os fatores sociais relativos ao crescimento da agroindústria canavieira, antes e depois da crise do mosaico, junto com o contexto das alternativas técnico-científicas envolvidas, também antes e depois da crise. É neste sentido que a História da Tecnologia tangencia outros aspectos do processo histórico, transcendendo as análises que apenas descrevem as técnicas, ou se limitam a apresentar as séries da produção.

\section{AS ORIGENS SOCIAIS DO PROCESSO DE MODERNIZAÇÃO \\ TECNOLÓGICA DA AGROINDÚSTRIA CANAVIEIRA PAULISTA}

No decorrer das duas primeiras décadas do século XX, a expansão cafeeira atingiu as regiões Central, Mogiana, Paulista e Araraquarense. Segundo Sérgio Milliet (1938, pp. 1-23), ao contrário de outras localidades por onde passou a cultura do café, a região Central manteve seu crescimento demográfico devido à diversificação da sua economia e à sua intensa urbanização, transformando-se junto com o resto do Estado num grande mercado para bens de consumo, entre os quais o açúcar. A agroindústria canavieira foi es- 
colhida pela elite política e econômica paulista como uma alternativa à cultura cafeeira por diversas razões já estudadas por vários autores. Dentre estas, podemos citar: a existência de uma demanda insatisfeita nos centros urbanos; o aumento dos preços do açúcar antes e durante os anos da Primeira Guerra Mundial; as sucessivas crises do café que propiciaram a transferência de terras e de capitais do café para a cana, principalmente após as crises de 1913 e de 1921 e, por último, mas não menos importante, o incentivo político à diversificação agrícola, e em particular à agroindústria canavieira. Por esses motivos, em algumas cidades da região Central, a lavoura canavieira nunca deixou de existir e caminhou lado a lado com a cafeicultura na sua expansão. Tanto na região Central como nas demais regiões, o ressurgimento da lavoura canavieira deu-se ora incorporando terras antes reservadas para a cultura do café, ora avançando sobre as terras já exauridas por aquela cultura (RAMOS, 1999, p.80). Como observaram Gnaccarini (1972, p.135) e Bray (1989, pp. 84-91), a maioria dos estabelecimentos produtores de açúcar pertencia a grandes fazendeiros de café ou a famílias que tiveram origem na produção cafeeira.

A indústria do açúcar mostrava-se tão vantajosa economicamente que atraiu o capital de uma empresa francesa, a Société de Sucreries Brésiliennes. Esta sociedade obteve lucros crescentes desde a sua fundação (1907) até os anos da crise do mosaico na década de 1920 (SZMRECSÁNYI, 1998, p.287). Faziam parte dessa sociedade as três principais usinas de açúcar do Estado paulista: a usina Rafard (Capivari), a usina Piracicaba e a usina de Porto Feliz, cuja produção conjunta, às vésperas da crise do mosaico, correspondia a cerca de 60\% da produção paulista de açúcar de usina (OLIVER \& SZMRECSÁNYI, 2000, p.7). Como identificou Szmrecsányi (1988, p.46), a agroindústria canavieira paulista teve seu crescimento relacionado à alta lucratividade, à proximidade dos mercados consumidores e às recorrentes crises de superprodução da economia cafeeira. Estes fatores atraíram um grande número de novos investidores que, durante as primeiras décadas do século XX, aumentaram constantemente a capacidade produtiva das fábricas de açúcar e o tamanho das plantações existentes, tendendo a deslocar o eixo da produção açucareira da região brasileira Norte-Nordeste para a região Centro-Sul, ainda na década de 1920. Assim, em função do constante crescimento do mercado interno, Szmrecsányi (1988, p.47) notou a ocorrência de uma expansão geral da agroindústria canavieira do Brasil e um aumento de sua competição interna, resultando em uma crise de superprodução no início da década de 1930.

Para esse autor, a crise de superprodução era uma questão de tempo, e só deixou de ocorrer já antes de 1930 por causa da crise do mosaico em 1925, a qual reduziu drasticamente a produção açucareira paulista ${ }^{3}$. Ainda segundo o 
mesmo autor, essa crise de superprodução evidenciou a ocorrência de mudanças não apenas quantitativas, mas também qualitativas, com a formação no País de uma estrutura de mercado fortemente oligopolista, apresentando uma descontinuidade tecnológica entre “...as empresas de grande, médio e pequeno porte...”, sendo as primeiras “... as únicas a possuir uma política de preços e um volume de produção autônomos, assim como a capacidade de pô-los em práti$c a$ ". Mesmo tendo sido iniciadas na década de 1920, as diferenças produtivas entre a região Centro-Sul e a região Norte-Nordeste ${ }^{5}$ e a tendência à diferenciação regional apresentaram uma breve pausa na década de 1930, retornando nos anos quarenta, mais precisamente após a Segunda Guerra Mundial.

Na década de 1930, durante os primeiros cinco anos mais incisivos da política do Instituto do Açúcar e do Álcool (IAA), nota-se uma intenção de anular tais diferenças produtivas, promovendo o incremento da produção das usinas da região Norte-Nordeste, e de interromper o processo de diferenciação regional, destinando aos produtores daquela região uma parcela da demanda do mercado do Centro-Sul. Através dessas medidas, a produção nordestina pôde continuar produzindo para o mercado interno, sem desfalecer diante da maior eficiência da produção paulista (SZMRECSÁNYI, 1979, pp. 172-3). Mas, segundo assinala o mesmo autor em trabalho posterior (1988, 40 p.58), é discutível o fato da agroindústria canavieira do Brasil ter crescido como um todo na década de trinta. Analisando o processo de transformação dos engenhos em usinas, Szmrecsányi nota que a produção açucareira na região Norte-Nordeste chegou a diminuir, apresentando também uma diferença negativa entre o aumento da produção das usinas e o decréscimo da produção dos engenhos. Já na região Centro-Sul, ainda que em escala menor do que na década de 1920, observa-se a manutenção do crescimento da produção, sustentado pelo aumento da produção de açúcar de engenho e particularmente pela produção de açúcar das usinas, responsáveis por $91 \%$ do incremento total da produção de açúcar no período entre 1930 e 1939 (SZMRECSÁNYI, 1988, p.59).

No caso do Estado de São Paulo, observa-se a tendência da sua produção superar a produção da região Norte-Nordeste nos anos de 1932, 1934 e 1937, quando, a despeito das políticas intervencionistas, atingiu o segundo lugar no total da produção de açúcar do País ${ }^{6}$. Isso iria acontecer em definitivo no início da década de 1950, mas os fatores estruturais para essa mudança já estavam presentes nas décadas anteriores. Para essa lenta mudança contribuíram as próprias medidas do IAA, as quais, ao fomentar a transformação do excedente de açúcar em álcool industrial e motor, propiciaram às grandes usinas a oportunidade de expandir a sua capacidade produtiva, através de destilarias anexas e da ampliação dos canaviais, bem como pela criação de no- 
vos estabelecimentos destinados exclusivamente à fabricação de álcool ${ }^{7}$. Além disso, as usinas paulistas contavam com a proximidade ao mercado consumidor, com a transferência de capitais e de terras do café para a cana, principalmente no momento seguinte à crise de superprodução de café, mantendo-se como tendência no decorrer de toda a década de 1940 (RAMOS, 1999, pp. 87 e 104). As usinas paulistas eram ainda beneficiadas pelo sistema de trabalho do colonato, que garantia um baixo custo da mão-de-obra e a extração de maiores lucros (GNACCARINI, 1972, p. 105).

Posteriormente, com a entrada do Brasil na Segunda Guerra Mundial e a conseqüente interrupção do comércio de cabotagem do Nordeste para o Sul do País, e com o desabastecimento do mercado, os usineiros paulistas tentaram diversas vezes eliminar a intervenção estatal, só restando ao IAA incentivar a produção de açúcar no Centro-Sul (SZMRECSÁNYI \& MOREIRA, 1991, p.60). Assim, no imediato pós-guerra, principalmente no Estado paulista, teve início a transformação dos engenhos criados durante a guerra em usinas e a conversão de destilarias em usinas de açúcar, dando início assim a um novo período de ampliação da capacidade produtiva a médio e longo prazos (idem).

Dessa forma, para Szmrecsányi (1988, p.64) o aumento da produção do Centro-Sul a partir de 1950 não deve ser entendido como um fato inusitado, mas como uma concretização de tendências e de lentas transformações estruturais iniciadas na década de 1920. Em síntese, foram esses os motivos sociais que levaram ao ressurgimento e ao crescimento da agroindústria canavieira paulista antes e depois da crise do mosaico. Cabe agora avaliar se a tecnologia, as novas variedades e os estudos sobre a cana, inseridos nas usinas cooperadas à Estação Experimental de Cana de Piracicaba, foram mais um fator social que contribuiu para essas mudanças quantitativas e qualitativas, o que em parte caracterizaria um processo de modernização tecnológica. Assim, nas próximas páginas procuraremos verificar se esse contexto há pouco relatado demandou a inserção de novas tecnologias, as quais, ao que tudo indica, resultaram nas mudanças qualitativas dos anos trinta e quarenta.

\section{O CONTEXTO DAS ALTERNATIVAS TECNOLÓGICAS DA AGROINDÚSTRIA} CANAVIEIRA PAULISTA ANTES DA CRISE DO MOSAICO.

Desde o início do século XX, a agroindústria canavieira paulista recebeu incentivos provenientes da Sociedade Paulista de Agricultura e, principalmente, da Secretaria de Agricultura do Estado (SZMRECSÁNYI \& VEIGA FILHO, 1998). Tais incentivos resultaram em uma série de estudos técnicos, entremeados de diretivas políticas, que mais cedo ou mais tarde acabavam sendo 
adotadas pelo governo paulista. Dentre esses estudos, merecem destaque os de Júlio Brandão Sobrinho de 1902 e de 1903 e o de Frederic H. Sawyer de 1905, sendo este republicado em 1908 (SZMRECSÁNYI, 1992, pp. 129 e 131).

O primeiro artigo de 1902, de autoria de Júlio Brandão Sobrinho, trazia suas impressões e perspectivas sobre a lavoura canavieira e a produção de açúcar na região de Ribeirão Preto. Para ele, já naquela época, as usinas daquela região eram superiores, em suas instalações industriais, às então existentes em Pernambuco, ou nas regiões de Campos (RJ) e de Piracicaba ${ }^{8}$. Já em seu segundo artigo ${ }^{9}$, as mesmas impressões tomam caráter político, com o autor defendendo abertamente uma maior diversificação agrícola e econômica do Estado, através do fomento da agroindústria canavieira e das fábricas de tecidos de algodão. Neste mesmo artigo, Brandão Sobrinho defendeu a transformação de centenas de engenhocas em usinas, e a fabricação de álcool para fins industriais e energéticos pelas empresas aguardenteiras. Ambas estas assertivas acabariam se confirmando anos mais tarde.

Já o estudo de Sawyer ${ }^{10}$, muito mais extenso e específico, levantou dados históricos, técnicos e comerciais das principais usinas daquela época, apresentando em destaque as usinas da Sucreries. Sawyer compartilhava das idéias expostas por Júlio Brandão Sobrinho, e também preconizou tanto a modernização das usinas quanto a racionalização da produção industrial, apontando para o desperdício na produção do açúcar e o descuido com os canaviais. Sawyer relatou que os canaviais ficavam aos cuidados do tempo e conforme os interesses dos colonos e que, por isso, as vantagens oferecidas pelas pesquisas feitas no Instituto Agronômico sobre seleção, adubação e tratos culturais em cana-de-açúcar não tinham boa aceitação ${ }^{11}$. Ainda assim, insistiu na necessidade do plantio de mudas selecionadas e na criação de “...um campo de experimentação com canas aclimatadas e satisfatórias: a riscada, a preta, a branca e a rosa"12 em cada usina. Este era um modelo de interação entre as empresas produtoras de açúcar e as estações experimentais públicas em algumas partes do mundo açucareiro que Sawyer bem conhecia ${ }^{13}$. Entretanto, ao longo das duas primeiras décadas do século XX, as iniciativas técnicas ficaram restritas à homogenização dos canaviais com as variedades Rosa, Preta e Riscada e à entrega dos canaviais aos cuidados dos colonos.

Estas duas alternativas tecnológicas também contribuíram ao longo do tempo para que as usinas obtivessem seus lucros através do aumento da área cultivada, tirando proveito da quantidade de cana ao invés da qualidade. Durante muito tempo as canas foram compradas e avaliadas por seu peso, e não pelo teor de sacarose e sanidade. Sobre as variedades preconizadas, houve quem discordasse, acreditando que os usineiros paulistas perdiam seu tempo, 
uma vez que poderiam importar outras recém-criadas que prometiam um alto teor de sacarose:

(...) Os nossos plantadores de cana estão desperdiçando seu tempo e dinheiro com a cultura de canas paupérrimas em açúcar. As canas que esses srs. enviam aos nossos engenhos muito pouco valem comparadas com as boas variedades obtidas de sementes nas Antilhas. Perdem os nossos agricultores só com isso, de $25 \%$ a $30 \%$, pois nossas canas são, $25 \%$ a $30 \%$ mais pobres em açúcar do que as boas canas de países adiantados nessa cultura. [...] O Congresso Federal votou a verba de 100 contos para a introdução de plantas e sementes... por Barbados passam vapores diretos para o Brasil; portanto, nada mais fácil do que a importação de um grande carregamento de mudas de canas selecionadas daquelas procedências. É preciso, é preciso. ${ }^{14}$

Entretanto, não se questionava o abandono dos canaviais aos cuidados dos colonos e a conseqüente ausência de modernos métodos de cultivo já conhecidos na época. Para entender essa estratégia, é preciso lembrar o contexto da agroindústria canavieira paulista, quando, na virada do século, apresentou seu primeiro grande impulso como resultado da transferência de terras e de capitais do café, o que gerou uma nova etapa no processo de aumento e concentração fundiária (RAMOS, 1999, p. 80). Entre 1894 e 1904 surgiram seis novas usinas, com a área cultivada passando de 9.365 ha para 48.719 ha, e a produção açucareira de 96 mil para 381.366 sacas de $60 \mathrm{~kg}$, incluindo-se nesse volume tanto a produção das usinas como a dos engenhos. Para este crescimento houve o interesse, a oportunidade e a demanda para a incorporação das variedades preconizadas pelo IAC, sem a melhoria dos tratos culturais e sem a criação de uma infra-estrutura técnico-científica de pesquisa e assistência técnica específicas à cultura da cana-de-açúcar.

Estes fatos revelam as características intrínsecas da agroindústria canavieira paulista da época e de suas relações com o progresso técnico, assim como a utilização de mão-de-obra sem qualificação e de baixa remuneração, a concentração fundiária, a baixa inversão de capital na parte agrícola, sendo a pesquisa financiada pelo Estado, e o incremento da produção através da modernização da parte industrial. Essas características históricas da agroindústria canavieira paulista, compartilhadas por outras monoculturas do Estado, deixaram possivelmente suas marcas na infra-estrutura criada para o desenvolvimento da ciência agronômica. Nesse primeiro momento, e no caso do Instituto Agronômico, nota-se nos seus relatórios anuais e em publicações como o Boletim da Agricultura, que os recursos físicos e humanos estavam todos voltados para pesquisas sobre a cultura do café e do algodão. Então, por 
exemplo, em resposta ao artigo sobre a necessidade de se importar novas variedades de cana, Carlos Botelho — secretário da Agricultura — advertiu Gustavo D’Utra (diretor do IAC) que não aconselhasse aos usineiros a importação de variedades da "moda" sem que antes fosse feita uma série de estudos ${ }^{15}$.

Para Carlos Botelho, os usineiros deveriam contentar-se com as variedades já preconizadas por aquela instituição, as quais, além de aclimatadas, não ofereciam riscos de veicularem doenças de difícil solução, colocando em perigo empresa tão lucrativa. O surgimento dessas doenças também poderia alterar o prestígio daquela instituição, caso não mostrasse a competência necessária para solucioná-las. Por isso, a medida tomada pelo secretário da Agricultura expressava a ambigüidade com que a política de diversificação da agricultura foi traduzida no Instituto Agronômico, o qual propagandeava a diversificação, mas não recebia os investimentos necessários para a atualização de sua infra-estrutura de pesquisa a todas as culturas. Esta posição causou a indignação de Gustavo D'Utra, o qual, em resposta, revelou através de seus conhecimentos científicos sua posição sobre a necessidade política de serem elaboradas pesquisas específicas para a lavoura de cana-de-açúcar:

(...) A cultura moderna não é mais tão somente empírica, ela dispõe de meios de pesquisa, e a hibridação, a criação de novas variedades é hoje um dos fatores mais potentes para o progresso da agricultura, tanto mais que, tratando-se de cana, os resultados já obtidos inspiram a maior confiança no futuro das melhores variadas criadas... Parece-nos que o Sr. Secretário procederia com acerto, fazendo importar as melhores variedades de canas vindas de semente e ordenando a criação de variedades paulistas pois as nossas canas, sujeitas desde séculos à seleção negativa, como o próprio Sawyer em vários lugares afirma, devem haver degenerado consideravelmente. ${ }^{16}$

Acreditamos ter sido em virtude deste contexto histórico - em seus aspectos políticos, econômicos, sociais, científicos e institucionais - que os usineiros não requisitavam do Estado pesquisas, a exemplo do que se fazia nas Estações Experimentais de Java, Barbados e Coimbatore — na Índia (como a criação de variedades por seleção e/ou cruzamento), e tampouco a contratação de especialistas em cana ou de agrônomos que fossem incumbidos de tal tarefa. Cessadas as importações de canas pelas iniciativas privada e pública, os canaviais paulistas livraram-se das doenças que vinham consecutivamente assolando os canaviais do mundo — tais como o sereh, a gomose e o mosaico. Mas, por outro lado, manteve-se inalterado o desenvolvimento técnicocientífico que visava a conjugar características agronômicas e econômicas à sanidade das canas. Assim, as iniciativas do IAC e do Serviço de Distribuição 
de Mudas e Sementes da Secretaria da Agricultura, em relação à cana-de-açúcar, foram mantidas com pouco esmero até a década de 1920. De fato, às vésperas da crise do mosaico, o Instituto Agronômico não podia contar com o auxílio da coleção de canas iniciada por Gustavo D'Utra, a qual ficou à revelia do tempo após a saída daquele pesquisador em 1908. Portanto, tendo em vista o contexto social em que se deu a introdução de uma nova tecnologia (canas aclimatadas pelo IAC), não é possível dizer que no início do século tenha se originado um processo de modernização tecnológica.

Contudo, os motivos para desencadear esse processo já estavam presentes, com a degeneração normal das canas e a oportunidade de aumentar a produção açucareira e os canaviais. Isso veio acontecer durante a Primeira Guerra Mundial, quando, no ano-safra de 1916/17, a agroindústria canavieira paulista alcançou o auge de sua produção (541.644 sacas de $60 \mathrm{~kg}$ ) e logo em seguida, por ocasião de uma forte geada no ano safra de 1917/18, houve uma redução da produção para 198.141 sacas de $60 \mathrm{~kg}$. Neste momento, houve novamente o interesse de importar novas variedades de cana. Uma das hipóteses sobre a entrada do mosaico no Estado de São Paulo argumenta que, em razão da aquisição de novas mudas para o replante dos canaviais, alguns usineiros decidiram importar uma pequena quantidade de variedades javanesas, provenientes da Argentina, as quais teriam veiculado o mosaico para São Paulo (QUEDA, 1998, p. 11).

A decisão de importar variedades javanesas provavelmente provenientes da Estação Experimental de Tucumán, logo após a geada de 1918, pode ser compreendida como uma hipótese razoável, uma vez que aquela estação tinha obtido sucesso na adaptação de variedades javanesas a seu clima, fortemente sujeito a geadas, e controlado a presença do mosaico ${ }^{17}$. Mas o controle não significava a eliminação do vírus do mosaico, a obtenção de canas com maior resistência ao mesmo, passíveis de serem modificadas conforme o meio em que são cultivadas. Por outro lado, as canas mais plantadas na época em São Paulo não apresentavam resistência, tornando-se alvos fáceis do vírus. Os dados sobre algumas usinas refletem a queda da produção no ano-safra da geada, uma retomada por volta dos anos-safra de 1921/22 e 1922/23, e depois uma contínua queda da produção como resultado da infestação pelo vírus do mosaico (OLIVER, 2001, p. 46).

Assim, pode-se perceber que, justamente no período da Primeira Guerra Mundial, em plena expansão do mercado interno, a agroindústria canavieira paulista foi primeiramente acometida pelos efeitos da geada, e depois deixada à sua própria sorte, com a importação de uma tecnologia para a qual ainda não havia um amparo institucional compatível. Este descompasso pode ser entendido quando verificamos quais foram as variedades de cana javanesas 
trazidas após a geada. Conforme uma classificação elaborada por EVENSON (1974), podemos afirmar que aquelas variedades possivelmente pertenciam ao segundo ou terceiro estágios de difusão da moderna tecnologia canavieira. Nestes estágios são intensas as atividades das estações experimentais na reprodução sexual das canas e na criação de novas variedades conjugando resistência às doenças e altos rendimentos. Parece razoável afirmar que as canas então importadas por São Paulo traziam em si, além das características alardeadas, conhecimentos tácitos que só poderiam ser adotados e difundidos através de treinamento especifico e de uma infra-estrutura científica que garantissem uma continuidade local das pesquisas iniciadas no exterior. Assim, no ápice da crise só restavam duas saídas para a agroindústria canavieira paulista: a ruína total, ou a recuperação e/ou criação de uma infra-estrutura técnico-científica, capaz de desenvolver uma resistência ao vírus do mosaico.

A ruína viria fatalmente se não fosse tomada qualquer iniciativa, ou se o problema fosse equacionado através de políticas tecnológicas errôneas. Por exemplo, no entendimento de Theodureto de Camargo (diretor do IAC na época), o mosaico era um problema fisiológico das canas e poderia ser resolvido através de tratos culturais. Por outro lado, alguns usineiros chegaram a cogitar o corte dos canaviais infectados, o que causaria a propagação do vírus em canas sem resistência, acarretando a total ruína da mesma forma. Este tipo de medida, ou de combate direto, extirpando as plantas atacadas, foi preconizado sem sucesso na Luisiania, Cuba e Porto Rico. Foi sabendo disso que o agrônomo José Vizioli ${ }^{18}$, encarregado de elaborar um plano de combate ao mosaico, propôs a substituição das variedades suscetíveis por resistentes e a criação de uma Estação Experimental de Cana. Devido a essas razões, e em face das pressões econômicas do momento, a resolução da crise foi tida como de primeira necessidade, vinculando-se à criação de uma infraestrutura de pesquisa que fornecesse assistência técnica especializada à lavoura de cana. De acordo com as idéias de José Vizioli, era preciso primeiramente agir com medidas emergenciais, para depois dar início às medidas a longo prazo - isto é, aos estudos agronômicos e aos trabalhos de melhoramento em cana já bem sucedidos em outros países (OLIVER, 2001, pp. 37-41 e 48). Entretanto, várias dificuldades surgiram no estabelecimento das medidas a longo prazo, consolidando assim um tipo de assistência técnica ainda bastante precário.

\section{Atividades E Trajetória da EstaÇão Experimental DE CANA DE Piracicaba}

Até a criação da Estação Experimental de Cana de Piracicaba (EECP) hou- 
ve um longo caminho; desde a primeira constatação do mosaico, feita por José Vizioli em 1923, até a sua efetiva criação, passaram-se quatro anos. Neste período, José Vizioli teve que provar sua competência científica e justificar a criação de uma Estação Experimental, a qual somente foi regulamentada em 1930 (OLIVER, 2001, pp. 48-54). Essas dificuldades, relacionadas ao desenvolvimento inicial da infra-estrutura de pesquisa em cana, fizeram parte de um processo de disputa institucional entre o Instituto Agronômico de Campinas e a Escola Superior de Agricultura "Luiz de Queiroz" (ESALQ), local onde a EECP permaneceu desde 1927 até o ano de 1945, mesmo pertencendo ao conjunto de estações experimentais do IAC a partir de 1935. Mas, esta é uma outra história, que merece atenção especial por envolver outros aspectos importantes, como a formação de agrônomos especializados pela ESALQ, a missão científica do IAC, e a própria história do desenvolvimento da Genética e da Fitopatologia no Brasil ${ }^{19}$. Mesmo levando em conta todas essas nuanças, que certamente influenciaram a trajetória da estação, para este trabalho importa identificar quais foram suas atividades e as conseqüências das mesmas no setor produtivo e para o início de um processo de modernização tecnológica.

O primeiro período da trajetória da EECP compreende os anos de 1926 a 1932, quando foram realizados os trabalhos de substituição das variedades. Num artigo publicado em O Estado de S. Paulo encontramos dados sobre seu patrimônio e sobre alguns de seus objetivos:

(...) 25hectares de terra, um prédio para sua sede com laboratórios e gabinete, uma casa para o chefe de culturas, galpão para máquinas, cocheira para os animais, "garages" para automóveis, depósito para materiais diversos e uma instalação completa para o estudo sistemático da irrigação dos canaviais. Situada na zona mais açucareira do Estado, em Piracicaba, junto à Escola Agrícola "Luiz de Queiroz", a Estação Experimental tem por objetivo primeiro a cultura racional da cana-de-açúcar, em todos os seus aspectos, transmitindo aos agricultores os resultados dos estudos experimentais que realiza. Investiga também os problemas relativos à exploração industrial da planta, designando a fabricação de álcool e açúcar, bem como questões pertinentes à climatologia e às terras paulistas, sob o ponto de vista cultural. ${ }^{20}$

De acordo com o plano desenvolvido por José Vizioli, uma grande campanha patrocinada pelo Estado foi realizada para promover a substituição das variedades. Em seis anos, as canas-de-açúcar Rosa e Preta cederam lugar a outras que apresentavam resistência ao vírus, as mesmas Javanesas POJ-36, 213 e 228, mas então provenientes de um rigoroso serviço de quarentena. A principal característica das variedades POJ era seu alto rendimento em toneladas 
por hectare, auxiliando o aumento da produção em conjunto com aumento das áreas de cultivo. No mesmo período foram também implantados os campos de experimentação e/ou cooperação nas principais usinas (OLIVER, 2001, pp. 54-59). Nestes campos de cooperação passaram a ser cultivadas diversas variedades para observar seu comportamento em diferentes solos e adubações. Além do objetivo explícito de modernizar a lavoura canavieira, o estabelecimento dos campos de cooperação servia de exemplo aos demais produtores, os quais se mostraram receosos a princípio, e não viram com bons olhos as canas javanesas, que eram visivelmente diferentes das canas tradicionais.

Essas medidas, conjugando a substituição de variedades aos trabalhos de cooperação nas principais usinas, acabaram propiciando uma vantagem a algumas usinas ante as políticas do IAA no início dos anos trinta, e deram início a um processo de modernização tecnológica, cujos efeitos podem ser parcialmente observados através do aumento da produção de açúcar de usina (QUADRO 1). Foi nesse período que antecedeu as políticas do IAA que a produção total do Estado passou de 742.170 sacas de $60 \mathrm{~kg}$ em 1927 para 1.350 mil em 1931. Tal aumento da produção foi baseado na crescente qualidade dos canaviais e, por serem as variedades javanesas mais fibrosas, alguns usineiros introduziram modificações nas moendas com o auxílio das Oficinas Dedini (RAMOS, 1999, p. 108). Sobre estes efeitos da substituição de variedades, Antônio Correia Meyer (agrônomo da EECP) comentou:

(...) As usinas que estavam acostumadas com as variedades antigas, cujo teor em fibras era muito reduzido e os processos de defecação, clarificação e concentração do caldo se realizavam com extrema facilidade, encontraram grandes embaraços e dificuldades ao trabalharem as canas javanesas de elevado teor em fibras. Todo o sistema de trabalho teve que ser modificado e novos aparelhos e maquinismos tiveram que ser adotados, e em pouco tempo as usinas apresentavam uma eficiência de elaboração e fabricação que resultou em magníficos rendimentos da produção. ${ }^{21}$

Além disso, outra frente de atuação foi formada, novamente por José Vizioli, o qual, como diretor da Divisão de Inspetoria e Fomento Agrícola da Secretaria da Agricultura do Estado de São Paulo, passou a representar os interesses dos usineiros paulistas em diversas comissões organizadas pelo governo federal até a consolidação do IAA em 1933, preconizando a fabricação de álcool - motor como saída para a superprodução de açúcar (OLIVER, 2001, pp.62-3). Ao mesmo tempo, os trabalhos anteriores de José Vizioli e a sua influência tanto na agroindústria canavieira paulista como na EECP também tiveram continuidade. Por outro lado, nos primeiros anos da década de 
1930, a EECP chegou a distribuir fermentos para a fabricação de álcool, mas esta atividade acabou desaparecendo com o correr dos anos.

Nossa hipótese da ocorrência de um processo de modernização tecnológica baseia-se na formação de um elo entre algumas usinas líderes e a EECP. Através dela supomos que possa ter havido a criação de um círculo virtuoso, integrando os estudos feitos nos campos de cooperação à escolha das novas variedades a serem estudadas e importadas pela EECP. Este mecanismo teria promovido um melhor domínio sobre a tecnologia empregada, adequando essa tecnologia à produção em larga escala, ao grande capital e às condições agronômicas do Estado de São Paulo. Deste modo, a “javanização” implicou uma mudança sem volta, pois essas variedades eram resistentes e não isentas de vírus. Isto levou a uma completa disseminação do vírus do mosaico em todos os canaviais paulistas, requisitando a realização de constantes avaliações sobre a sua sanidade, rendimentos e interações agronômicas e industriais diversas, como já previra José Vizioli em 1926 ao dizer que as:

(...) variedades javanesas, merecem o cuidado exigido pela presença de pragas e moléstias da planta, principalmente de combate às mesmas, escolha de roletes, adubação e modificação geral dos processos de cultura, visando em particular o emprego de máquinas agrícolas apropriadas a esta lavoura. ${ }^{22}$

Além disso, novas variedades só poderiam ser preconizadas depois de estudos e comparações. Estes trabalhos eram realizados tanto na EECP como nas usinas cooperadas sob a forma de ensaios e de competição de variedades. Por enquanto, a falta de dados em série sobre as áreas cultivadas e as toneladas de cana moídas pelas usinas cooperadas não permitem caracterizar com precisão todos os efeitos da inserção da nova tecnologia. Mas, pode-se notar uma correlação entre as usinas cooperadas e as usinas líderes, a sua crescente produção, crescentes rendimentos e a manutenção de uma alta participação na produção total do açúcar de usina para o período até 1938 (ver a respeito o QUADRO 2). Esta foi possivelmente uma das características do processo de modernização, que se apresentou de forma sutil durante as décadas de 1930 e de 1940, mas certamente se tornou mais acentuada a partir da década de 1950, quando teve início um programa de melhoramento, resultando nas primeiras variedades de cana paulistas ${ }^{23}$.

No segundo período, após 1932, quando a substituição foi completada de acordo com os planos de José Vizioli, nota-se uma retomada do crescimento da produção de açúcar de usina, uma recuperação dos rendimentos industriais e um aumento da produção de álcool, no mesmo momento em que as quotas estabelecidas pelo IAA foram alcançadas (ver QUADRO 1). Paralela- 
mente a essas conseqüências da substituição de variedades, entre 1932 e 1946, a EECP manteve suas terras ocupadas com a criação e multiplicação de variedades, como as variedades indianas - $\mathrm{CO}$, cujas características compreendem altos teores de sacarose e de tonelada por hectare.

Segundo a classificação elaborada por Evenson (1974, p.59) a difusão internacional das variedades indianas nas décadas de 1930 e 1940 representou um quarto estágio de difusão da tecnologia em cana. No presente estudo, este dado nos possibilita argumentar que os agrônomos da EECP já tinham recuperado parte do tempo perdido, mantendo-se atualizados e em contato com os principais centros de pesquisa em cana do exterior. Por outro lado, entre 1935 e 1946, nota-se que todas as usinas cooperadas desenvolveram estudos com essas variedades, além de estudos que correlacionavam diferentes variedades à época de corte e estudos de adubação (OLIVER, 2001, pp. 94 e 96). Tais estudos correspondiam ao que se fazia em outras Estações Experimentais do exterior e colocavam o Brasil dentro de uma rede de pesquisa internacional. Apesar de ainda figurar na categoria dos importadores de tecnologia voltados para a reprodução de mudas por seleção, foi possível à EECP armazenar dados e treinar seu pessoal para melhor compreender as características específicas dessas variedades, principalmente no que se referia à sua adaptação às condições locais e, num momento posterior, sobre a resistência das mesmas ao vírus do mosaico.

Um outro avanço que podemos apontar nesse período refere-se ao aumento do número de usinas que instalaram campos de cooperação com a EECP — de oito em 1935, para 18 ao final da década de 1940, número que se manteve quase inalterado durante os anos da Guerra (OLIVER, 2001, p. 142, tabela 4.4). Ao lado deste aumento de usinas cooperadas, observa-se um aumento da distribuição de mudas em função da crescente demanda a partir de 1937 até 1940: de 740.250 para 1.175.905. Este fato parece refletir o que ocorreu no período, com a entrada de novos produtores no setor, distanciando a EECP das pesquisas a longo prazo (ou da criação de variedades paulistas), e promovendo a necessidade de aumentar seus campos de propagação de mudas. Este fato deve ser entendido como reflexo direto do processo de modernização em curso e como uma adaptação às demandas da lavoura de cana em geral, e não como um evento planejado pela EECP. Para reforçar essa afirmação basta dizer que nas diretrizes da EECP existiam outros itens que foram parcialmente contemplados e outros totalmente abandonados, como pudemos verificar em seus relatórios anuais. Entretanto, diante desta adaptação às necessidades da agroindústria canavieira paulista, e devido à ausência novamente de cuidados fitosanitários, a distribuição de mudas teve que ser reduzida, entre 1941 e 1946, até que a variedade CO estivesse livre do vírus do mo- 
saico em 1947, e também até a compra de novas terras para a EECP em 1945, dando início a um terceiro período de sua trajetória.

Esse terceiro período compreende os anos posteriores a 1947, durante os quais houve uma consolidação da assistência técnica às principais usinas e um retorno à idéia de estabelecer um programa de melhoramento interinstitucional a longo prazo. A elaboração desse plano, com metas semelhantes àquelas elaboradas por José Vizioli (OLIVER, 2001, pp.56-7), parece indicar que o processo de modernização tecnológica então em curso pode ter desencadeado na infraestrutura de pesquisa da EECP avanços incrementais, requisitando o constante treinamento de agrônomos, estabelecendo relações interinstitucionais para o melhor aproveitamento das capacidades científicas já estabelecidas, e consolidando a assistência técnica à pesquisa. Como possíveis reflexos desse terceiro período na produção das usinas, observamos que, ao término da Segunda Guerra Mundial, houve um aumento da produção de açúcar de usina (veja-se QUADRO 1). Mas, novamente, a falta de dados não nos possibilita afirmar se e quanto desse aumento esteve relacionado à distribuição das novas variedades isentas do vírus do mosaico, principalmente porque foi somente em 1947 e 1948 que a distribuição de mudas de cana atingiu novamente os volumes máximos de 886.675 e 1.034 .715 respectivamente. Naquele momento, o que se observa é uma crescente fama da estação entre os usineiros, ganhando destaque também na ESALQ e na cidade de Piracicaba.

Para finalizar, devemos observar em detalhe quais foram as usinas envolvidas, podendo traçar mais claramente qual foi o elo entre as usinas líderes, as usinas cooperadas e a EECP durante todo aquele período. No trabalho de Ramos (1999, p. 101) temos um registro dos principais grupos de usineiros para o período entre 1930 a 1945, em ordem decrescente: Societé de Sucreries Brésiliennes, Morganti (Refinadora Paulista), Francisco Junqueira, Matarazzo, Alves Almeida, Família Nogueira, G. Schmidt \& Irmãos, Reis Magalhães, Francisco Frascino, João B.L. Figueiredo e Monteiro Barros. No total de açúcar produzido por usinas do Estado, os principais grupos apresentaram uma participação conjunta de $85,1 \%$ no período de $1930 / 31$ a 1935/36, de 78,6\% entre 1936/37 e 1940/41, e de 73,1\% entre 1941/42 e 1945/46.

No QUADRO 3 notamos que, com a exceção de quatro grupos, sete se beneficiaram diretamente dos trabalhos da EECP no período que compreende a fase mais incisiva das políticas do IAA. Somente os grupos G. Schmidt \& Irmãos, Alves Almeida, Francisco Frascino e Monteiro Barros não apresentam essa correlação, sendo que os grupos Francisco Frascino e Monteiro Barros aparecem apenas como grupos principais nos períodos de 1936/37 a 1940/41 e de 1941/42 a 1945/46 respectivamente. Já no período seguinte entre 1946/7 e 1950/51 (RAMOS, 1999, p. 138), observamos que os seis primei- 
ros grupos eram os mesmos seis primeiros do período anterior, na mesma ordem: Societé de Sucreries Brésiliennes, Morganti (Refinadora Paulista), Francisco Junqueira, Matarazzo, Alves Almeida, Família Nogueira, deixando de figurar os grupos Reis Magalhães, G. Schmidt \& Irmãos, Francisco Frascino, João B.L. Figueiredo e Monteiro de Barros. Em compensação, houve o ingresso dos grupos Irmãos Ometo e Irmãos Biagi, que também se beneficiaram diretamente das atividades da EECP. Nesse período a participação dessas usinas no total de açúcar de usina produzido no Estado caiu para $25 \%$, mas no total de açúcar produzido no estado contribuíram com 62,5\% (RAMOS, 1999, p.138). Isto se deveu ao fato de ter aumentado o número total de usinas de 38 (1941-1945) para 76 em 1946 e 92 em 1950, em relação ao declínio da produção dos engenhos no Estado.

Em linhas gerais, podemos dizer que as medidas técnico—científicas aplicadas pela EECP alinharam - se às políticas do IAA para o Estado de São Paulo, potencializando os rendimentos das usinas (RAMOS, 1999, pp. 100/1) até 1938. Após o início da Segunda Guerra Mundial (1939) e com a promulgação do Estatuto da Lavoura Canavieira (1941), as atividades da EECP tenderam a ampliar o número de beneficiados, principalmente através da distribuição de mudas que auxiliaram no plantio de novos canaviais das usinas, de engenhos e de fornecedores de cana. Mas, como vimos anteriormente, essa tendência não interrompeu o vínculo da EECP com as principais usinas. Deste modo, notamos três momentos em que o contexto propício ao aumento da produção requisitou a inserção de tecnologia nas principais usinas do Estado: a introdução das canas javanesas antes das políticas do IAA; o crescimento regular entre 1932 e 1946 alinhado às políticas daquele órgão federal, possivelmente como resultado da inserção da variedade $\mathrm{CO}$ e da sua posterior degenerescência pelo mosaico, e o grande crescimento ao término da Guerra e durante toda a década de 1950, o qual coincide com a purificação da variedade $\mathrm{CO}$ e com elaboração de um programa de melhoramento.

\section{CONSIDERAÇÕES FINAIS}

De acordo com o que foi aqui evidenciado, podemos sugerir que o início do processo de modernização tecnológica deu-se a partir da substituição de variedades e do estabelecimento de uma aliança entre a EECP e as usinas líderes. Este processo possivelmente teve como carro chefe as usinas-líderes e cooperadas, cujas demandas oriundas das condições político-econômicas propícias e da manutenção do mosaico nos canaviais interferiram nas atividades e na trajetória da EECP. Assim, considerando que o processo em questão teve 
início com a existência de uma demanda econômica conjugada à oferta de uma nova tecnologia, a qual era amparada por uma infra - estrutura flexível e contínua, as adaptações sofridas nas atividades da EECP podem ser classificadas como reflexos das conseqüências da modernização tecnológica nas usinas líderes e cooperadas. Este processo poderá vir a ser confirmado quando essas usinas forem estudadas pormenorizadamente. Em seus arquivos deverão ser buscados dados exatos sobre a produção agrícola e industrial, a intensidade e as conseqüências diretas dos trabalhos da EECP. Somente com esses dados será possível caracterizar um processo de modernização tecnológica que retrate os efeitos específicos da tecnologia inserida na produção, seus reflexos nas atividades da EECP e o retorno nas usinas, mostrando-o como um processo endógeno ou continuamente alimentado e vinculado a uma nova etapa de desenvolvimento econômico.

Desde já observamos que, por estar restrito a determinadas usinas, o processo de modernização tecnológica não transparece nas análises sobre a agroindústria canavieira paulista como um todo, nas quais notamos baixos rendimentos agronômicos e industriais. Para Ramos (1999, p.115), estes índices são o resultado de uma estrutura recém-estabelecida e baseada no expansionismo agrário, também comum a outras regiões e agroindústrias canavieiras do País. Contudo, nessas regiões, mesmo com a introdução das novas variedades, não se deu qualquer desenvolvimento semelhante. Olhando para o presente, não pode ser ignorado o fato de que as atividades da EECP continuaram tendo a sua importância entre determinado grupo de usineiros, através do lançamento de novas variedades e da assistência técnica em geral. Trata-se de um conjunto de atividades bem conhecidas desde fins da década de 1920, e que nos possibilita entender o progresso técnico como um fato social e uma condição estrutural, ao lado das estruturas fundiária e de mercado. A crise do café e as políticas do IAA no início da década de 1930 só vieram reforçar e direcionar o que já estava para acontecer. Absolutamente imbricadas na sociedade e ao seu tempo, as novas variedades de cana-de-açúcar introduzidas nas usinas paulistas em fins da década de 1920 atuaram como mais um fator no estabelecimento de uma aliança entre a nova classe usineira e o poder público do Estado. 


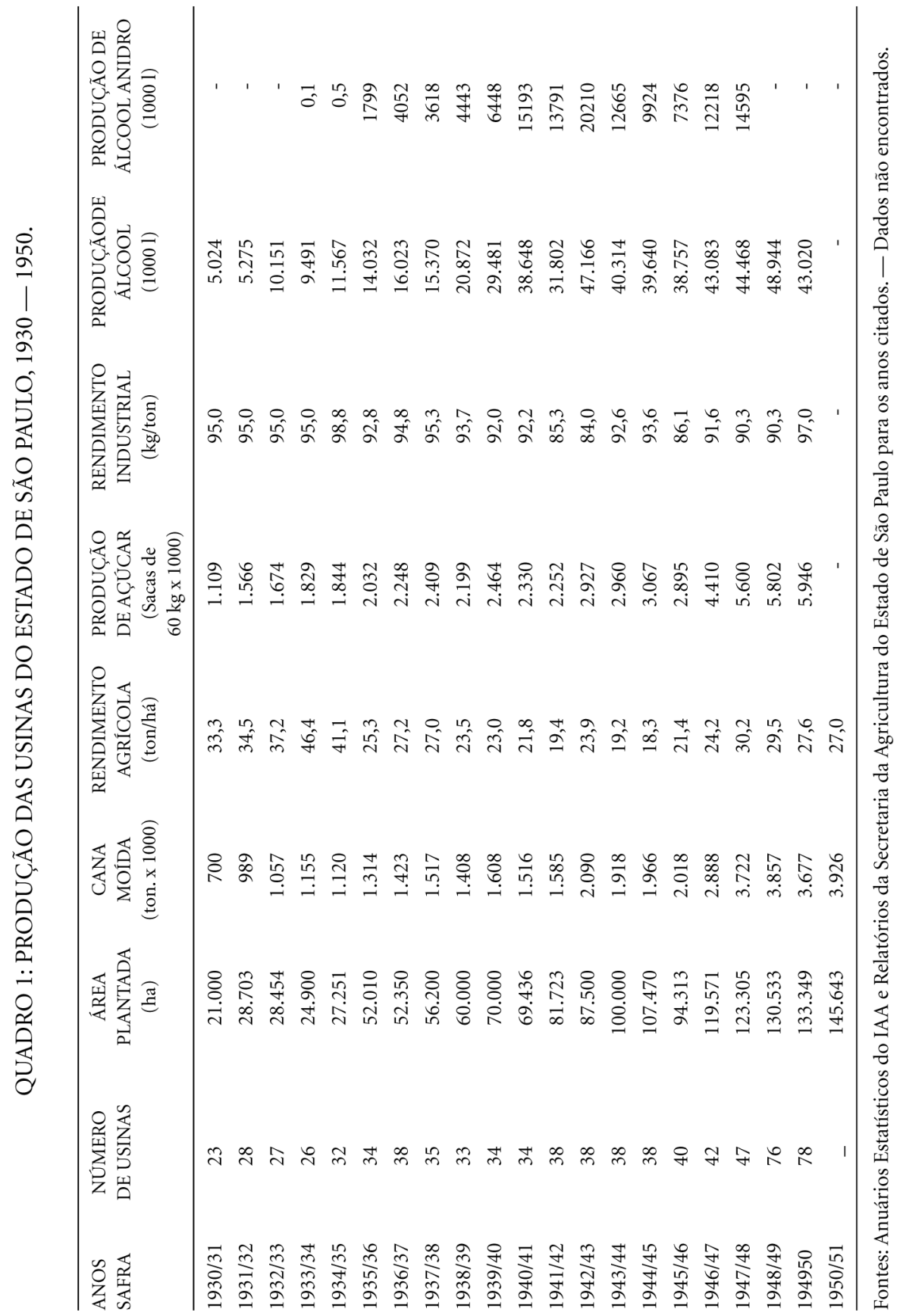


A Estação Experimental de Piracicaba e a modernização tecnológica da agroindústria...

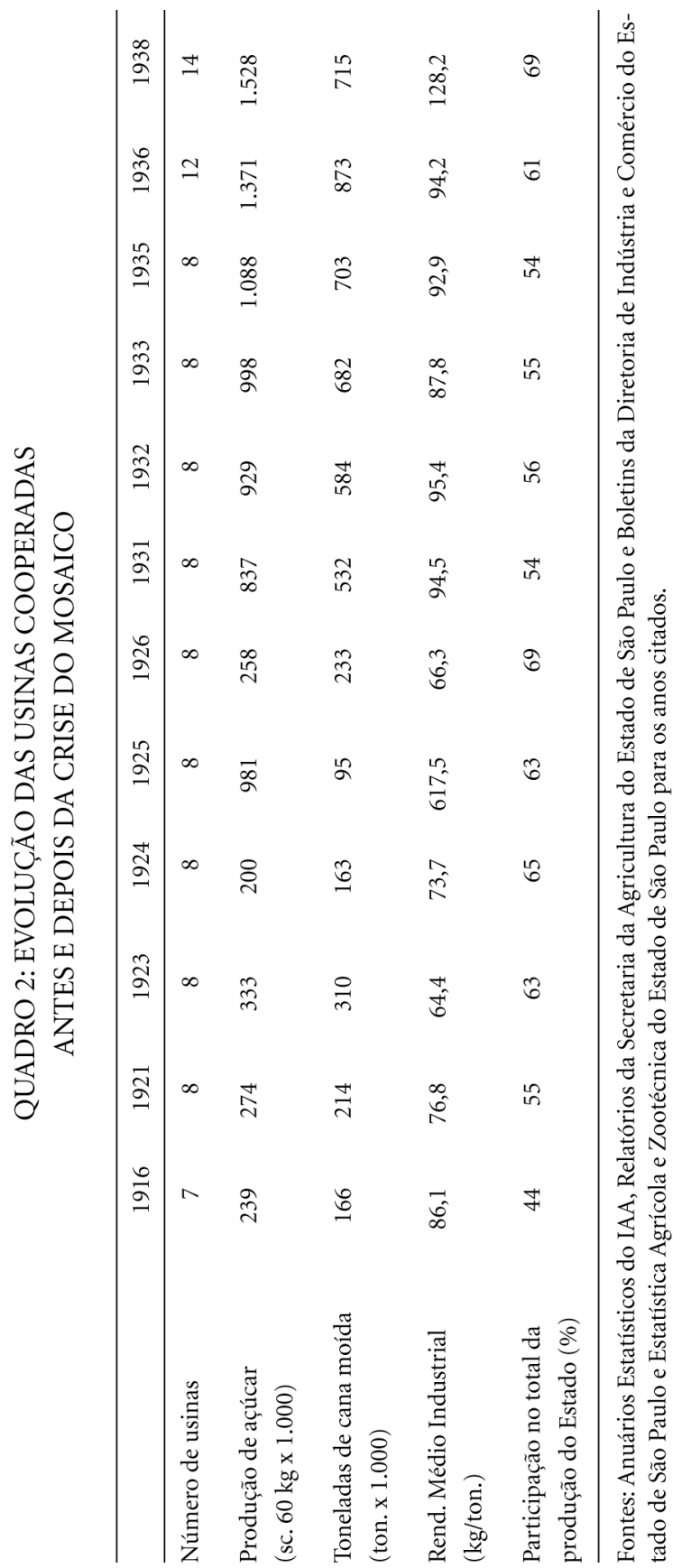




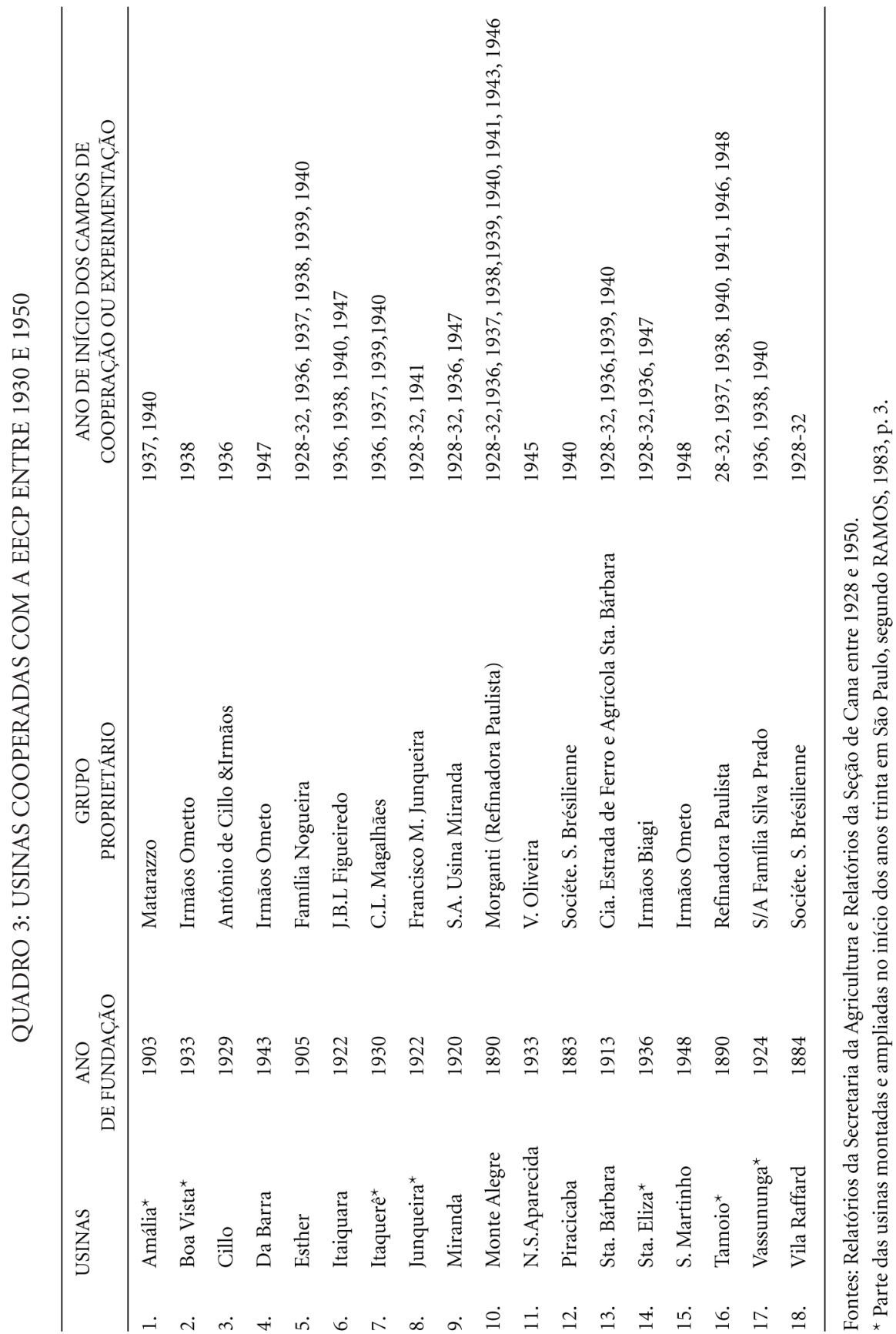

Revista Brasileira de História, vol. 23, nº 46 


\section{BIBLIOGRAFIA.}

BRAY, Silvio. Formação do Capital na Agroindústria Açucareira de São Paulo: Revisão de paradigmas tradicionais. Rio Claro: IGCE/UNESP, Tese de Livre-Docência, 1989.

EVENSON, Robert. International Diffusion of Agrarian Technology. Journal of Economic History XXXIV (1), mar., 1974, pp. 51-73.

GNACCARINI, José. Estado, Ideologia e Ação Empresarial na Agroindústria Açucareira de São Paulo. São Paulo: FFLCH/USP, Tese de Doutorado, 1972.

LANDELL, Marcos e ALVAREZ, Rafael. Cana-de-açúcar. In: O Melhoramento de Plantas no Instituto Agronômico. Campinas: Instituto Agronômico, 1993, pp.77-93.

MILLIET, Sérgio. Roteiro do Café e outros ensaios: contribuição para a história econômica e social do Brasil. São Paulo: 1938 (1ª edição).

OLIVER, Graciela. José Vizioli e o início da modernização tecnológica da agroindústria canavieira paulista, 1919 - 1949. Campinas: DPCT/IG/UNICAMP, Dissertação de Mestrado, 2001.

e SZMRECSÁNYI, Tamás. A crise do mosaico e a modernização tecnológica da agroindústria canavieira paulista, 1920 - 1950. Comunicação apresentada nas XVII Jornadas de História Econômica, Tucumán, 20,21 y 22 de setembro, 2000 (disponível em CD-Rom).

PRADO JÚNIOR, Caio. História Econômica do Brasil. São Paulo: Brasiliense, 1994 (1945).

QUEDA, Oriowaldo. A Intervenção do Estado e a Agroindústria Açucareira Paulista. Piracicaba: ESALQ/USP, Tese de Doutorado, 1972.

A Importância e os Impactos da Declaração do Mosaico e o crescimento da Lavoura Canavieira no Estado de São Paulo (1923-1940). Comunicação apresentada no Simpósio Los Complejos Azucareiros em la Argentina y Brazil: Aspectos Sociales y Politicos, 1890-1945, XVI Jornadas de Historia Econômica, Quilmes, Argentina: 16-18 de setembro de 1998.

RAMOS, Pedro. Um Estudo da Evolução e da Estrutura da agroindústria canavieira do Estado de São Paulo. São Paulo: FGV, Dissertação de Mestrado, 1983.

- Agroindústria Canavieira e Propriedade Fundiária no Brasil, São Paulo: Hucitec, 1999.

SZMRECSÁNYI, Tamás. O Planejamento da Agroindústria Canavieira do Brasil (1930 1975). São Paulo: Hucitec, 1979.

. Crescimento e crise da agroindústria açucareira do Brasil, 1914 - 1939. Revista Brasileira de Ciências Sociais, vol. 7, n. 5, jun., pp. 32-68, 1988.

. Pequena história da agricultura no Brasil. São Paulo: Contexto, 1990. 
. Agrarian bourgeoisie, regional government and the orings of São Paulo's modern sugar industry, 1870 -1930. Cadernos do Instituto de Geociências, Campinas: IG/UNICAMP, vol. 2, n. 1, pp. 128-129, 1992.

. Origens da Liderança Científica e Tecnológica Paulista no século XX. Textos para Discussão no.15. Campinas: DPCT/UNICAMP, pp. 1-19, 1996.

. A French Free-Standing Company in Brazil's Sugar Industry: a Case Study of the Société de Sucreries Brésiliennes, 1907 - 1922. In: The Free-Standing Company in the World Economy, 1830 - 1996. Oxford: University Press, 1998, pp.279-290.

e MOREIRA, Eduardo. O Desenvolvimento da Agroindústria Canavieira do Brasil desde a Segunda Guerra Mundial. Estudos Avançados, 11(5), pp. 57-79, 1991.

e VEIGA FILHO, Alceu A. O Ressurgimento da Lavoura Canavieira em São Paulo na Primeira República, 1890 - 1930. Travesia, Tucumán: Universidade Nacional de Tucumán, nº 2, pp.67-81, 1999.

TOKESHI, H. Doenças da cana-de-açúcar (híbridos de Saccharum spp.). In: Manual de Fitopatologia. São Paulo: Agronômica Ceres, 1995 (1ª edição), pp. 207-225.

\section{NOTAS}

${ }^{1}$ Este artigo é resultado da Dissertação de Mestrado - José Vizioli e o início da modernização da agroindústria canavieira paulista, 1919 - 1949, desenvolvida com o apoio da FAPESP (proc. 99/11176-3), sob a orientação do Prof. Dr. Tamás Szmrecsányi.

${ }^{2} \mathrm{Na}$ literatura recente de Fitopatologia, o agente causador do mosaico é conhecido como Sugar Cane Mosaic Vírus (SCMV) ou simplesmente vírus do mosaico. Recebeu este nome por causar nas folhas da cana-de-açúcar estrias brancas que formam uma espécie de mosaico (TOKESHI, 1995, pp. 207-225.)

${ }^{3}$ Caio Prado Jr. já tinha esboçado a mesma opinião sobre o papel da crise do mosaico na crise de superprodução no início da década de 1930: "Nos anos anteriores a esta data, a produção paulista será gravemente afetada pelo alastramento do mosaico, a grande praga da cana. A substituição dos canaviais paulistas por variedades mais resistentes reerguerá a produção do Estado. As regiões do Norte sofrerão menos com a praga e gozarão assim de um período de relativo desafogo. Com a restauração paulista, a crise do Norte chegará ao máximo" [PRADO JUNIOR, 1945 ( $1^{\underline{a}}$ edição), p. 245, nota 79].

${ }^{4}$ SZMRECSÁNYI, 1988, p.50.

${ }^{5}$ Já no período entreguerras, os níveis de produção média por usina eram maiores principalmente nos Estados de São Paulo e Rio de Janeiro do que nos Estados da região NorteNordeste, sugerindo uma diferenciação na capacidade e eficiência produtiva entre as duas regiões (SZMRECSÁNYI, 1988, p.58). 
${ }^{6}$ SZMRECSÁNYI, 1988, p.64.

${ }^{7}$ SZMRECSÁNYI \& MOREIRA, 1991, p.60.

${ }^{8} \mathrm{~A}$ indústria Açucareira no $3^{\circ}$. Distrito Agronômico, Boletim de Agricultura, São Paulo: Typ. Oficial, 1902, pp. 519-527.

${ }^{9}$ Lavoura de Cana e de Algodão e Indústrias de Assucar e de Tecido no Estado de São Paulo, Boletim de Agricultura, São Paulo: Typ. do Diário Oficial, 1903, pp. 559 —606.

${ }^{10}$ Secretaria de Agricultura, Comércio e Obras Públicas do Estado de São Paulo, Relatório Apresentado à Sociedade Paulista de Agricultura... por Frederic H. Sawyer... Representante da mesma sociedade na Conferência Assucareira do Recife, São Paulo, Typ. do Brazil, 1905.

${ }^{11}$ Idem, pp.92-3. Desde o primeiro estudo, feito por Dafert e Bollinger em 1892, até as iniciativas de Gustavo D'Utra nos primeiros anos do século XX, o Instituto Agronômico preconizava essas variedades como as melhores para o Estado de São Paulo. Estas variedades apresentavam como característica um alto rendimento de canas por hectare, sem no entanto mostrar um alto teor de sacarose.

${ }^{12}$ Idem, p.91.

${ }^{13}$ Como seu próprio estudo revela, Sawyer compara as empresas açucareiras paulistas às de Java, Havaí e Cuba.

${ }^{14}$ Anônimo, Boletim da Agricultura, São Paulo: Typ. do Diário Oficial, 1904, pp.463, 465 e 466.

15 “... devereis, o quanto possivel, banir da vossa atenção aquelas variedades que, embora riquíssimas em princípios sacarinos, se mostrem sujeitas às numerosas pragas que danificam a cana e as que fazem de difícil cultivo e pouco vigorosas, só recomendando ao critério do lavrador aquelas que após repetidas análises e seguidos experimentos culturais, ficarem positivamente reconhecidas como dignas de alta recomendação dessa instituição de pesquisa agrocientífica que, estou convencido age, como é da sua missão, com o maior escrúpulo e segurança no que afirma e recomenda", BOTELHO, Carlos. Boletim da Agricultura, São Paulo: Typ. do Diário Oficial, 1904, pp. 351-2.

${ }^{16}$ D’UTRA, Gustavo. Boletim da Agricultura. São Paulo: Typ. do Diário Oficial, 1904, pp.577-8.

${ }^{17}$ FAWCET, G. L. El mosaico de la caña de azúcar, Circular da Estación Experimental de Tucumán, nº 10, 1923, pp. 1-4.

${ }^{18}$ José Vizioli nasceu em Piracicaba e era filho de imigrantes. Formou-se como agrônomo em 1917 na ESALQ, seguindo para os Estados Unidos para fazer um curso de especialização, um prêmio dado pelo Estado de São Paulo aos melhores alunos daquela Escola de Agronomia.

${ }^{19}$ É provável que o desenvolvimento desses trabalhos de pesquisa e assistência técnica na EECP tenham renovado o papel do agrônomo como técnico pesquisador, tendo sido essa Estação a primeira criada pelo Estado de São Paulo. O sucesso dos trabalhos realizados na 
EECP também pode ser avaliado no contexto institucional do IAC, o qual, a partir da reforma de 1935, passou a ter diversas Estações Experimentais no Estado, a exemplo daquela criada em Piracicaba.

${ }^{20} \mathrm{~A}$ indústria açucareira do Estado de São Paulo - A estação Experimental de Cana de Piracicaba - O programa dos seus trabalhos - dados interessantes - Fala-nos a propósito do Dr. Antônio Correa Meyer. O Estado de S. Paulo, 7 de setembro de 1933.

${ }^{21}$ A produção de açúcar no corrente ano é a maior verificada no Estado de São Paulo - o que diz à Folha da Manhã Antônio Correa Meyer, Folha da Manhã, 1931.

${ }^{22}$ VIZIOLI, José. A presente situação da indústria açucareira no Estado de São Paulo, Boletim da Agricultura. São Paulo: Typ. do Diário Oficial, 1926, p. 341.

${ }^{23}$ Um primeiro programa de melhoramento teve início ainda na década de 1930, mas não foi levado adiante porque os trabalhos de seleção e multiplicação das mudas tomaram todo o tempo e atenção do diretor da estação José Manuel Aguirre (OLIVER, 2001, p.96). Somente a partir de 1950 que novos cruzamentos foram feitos, contando com a ajuda de diversas outras instituições. Como resultados destes trabalhos, merecem destaque as variedades IAC50-134, IAC51-205 e IAC52-150 (LANDELL \& ALVAREZ, 1993, p.85).

Artigo recebido em 3/2002. Aprovado em 8/2003.

Revista Brasileira de História, vol. 23, nº 46 